\title{
Non-native EFL Teachers' Perception of English Accent in Teaching and Learning: Any Preference?
}

\author{
Ruth Wong \\ The Education University of Hong Kong, Hong Kong SAR, China
}

\begin{abstract}
This study studied the accent perception of a group of non-native pre-service EFL teachers in Hong Kong in order to see whether native English norm is of their preference for teaching and learning. Results found that participants all preferred traditional native English as learning model and seemed to have overlooked the principle of intelligibility, even there had been calls for using lingua franca core as learning model. Results show that participants all preferred using native English to be the model of teaching and learning. Among all the native English varieties, participants preferred the accent from the United Kingdom though not all could identify the accent they preferred. The study showed there was a mismatch between what the participants preferred and their ability of identifying accents of different kinds.
\end{abstract}

Index Terms - accent, immersion, EFL

\section{INTRODUCTION}

The well-known sociolinguistic profile of English is proposed by Kachru (1985). He categorized English within three concentric circles - the inner circle, the outer circle and the expanding circle. The inner circle refers to the traditional native English speaking countries like USA, UK and Canada. The outer circle includes countries where English is spoken as a second language like India and the Philippines. Expanding circle comprises countries where English is spoken as a foreign language by non-native speakers of English (e.g. China and Japan). The model proposed by Kachru is not static and among these circles, the expanding circle is the fastest growing circle.

With the increase number of non-native English speakers in the outer circle, English in the world has led to the emergence of many different varieties of English and the concept of whether native pronunciation should be followed by EFL learners has been greatly discussed and challenged (e.g. Erling, 2005). Research to date has found native English is preferred by most learners and they would like to adhere to the native English models like either General American (GA) or Received Pronunciation (RP) (e.g. Bayard, Gallois, Ray, Weatherall, \& Sullivan, 2002; Chiba, Matsuura, \& Yamamoto, 1995; Dalton-Puffer, Kaltenboeck, \& Smit, 1997; Timmis, 2002) and only very few studies found that learners of English would not like to speak like a native speaker (Widdowson, 1997; Yano, 2001).

Preferred accent and perception

EFL learners preferred learning English within the norm of GA or RP for different reasons. Bayard, Gallois, Weatherall, \& Sullivan (2002) found learners from Europe and Southeast Asia preferred GA because of the popularity of American media worldwide. Dalton-Puffer, Kaltenboeck \& Smit (1997:122) found that Austrian learners would rate a native English accent higher which was of their own familiarity, i.e. Austrian-British one. Austrian learners described the speakers with the RP accent as "the most educated, organized, and courteous". Danish learners also found RP "to be the unsurpassed prestige variety" and it is the correct model of pronunciation in Danish EFL classrooms (Ladegarard, 1998).

Meanwhile in Asia, Hu (2004) found that $100 \%$ of the respondents at a Chinese university regarded British and American accents to be the only English standards and he believed that this deeply rooted belief was inculcated in the minds of the teachers. In Japan, Japanese undergraduate students also rated the UK and the GA accents higher than those of the expanding circle like Sri Lanka, Malaysia and Hong Kong (Chiba, Matsuura, \& Yamamoto, 1995). In Li's (2009) study, $80 \%$ of the educated Chinese bilingual users also preferred native English accent. A much larger scale of study was conducted by Timmis (2002), he sampled 400 learners in more than 45 countries and found them prefer native speaking norms in speaking and grammar.

The above studies have proved what Scales, Wennerstrom, Richard and Wu (2006) said about learners of expanding circles tended to set native English standards for their own speech and the above studies have also echoed how Kramsch (1993:9) put it, "Nonnative teachers and students alike are intimidated by the native speaker norm". Both students and teachers are being led by the norms and standard of native English. For EFL students, achieving native standard of English seems "unattainable" because EFL learners are not L1 speakers and they can never be native speakers, and will never be. For non native English speaking EFL teachers, they are also intimidated by their own past learning experience, classroom language standard of native English teachers, and very often, the available teaching and learning materials 
are of native English standard and the materials "teach them what English is, what is not" hence cause EFL learners to identify native English as the "norm". Even Levis (2005) pointed out that there are two main principles of pronunciation teaching - nativeness principle and intelligibility principle - in EFL teaching and learning context, the emphasis on nativeness principle is still yet lopsided and the principle of intelligibility is often neglected. As Cook (1999) and Hutchinson \& Hutchinson (1994) described most teaching and learning materials are mainly inclined to the "nativeness" model. All these have in turn led teachers to think and believe their English is not the standard but that of the native speakers.

\section{World Englishes}

With the reality that most EFL learners prefer setting native English as the norm of learning, the issue of intelligibility in communication seems to be neglected. A recent study conducted by Li (2009) found that only $20 \%$ of the Chinese bilingual users preferred a localized English accent because of their concerns over the issue of intelligibility. Many scholars like Cook (1999) are critical of the hegemony of using native English as the teaching and learning model. Scholars emphasized the importance on global intelligibility in world Englishes, rather than on a particular native variety of English (e.g. Crystal 1997; Jenkins, 2005, 2006, 2007; Kachru, 1997, Kirkpatrick, 2006, 2007; McKay, 2002; Seidlhofer, 2004, 2006).

Jenkins (2005) raised a "lingua-franca core" as the model for pronunciation teaching so as to preserve the particular variety of English as part of their culture and identity because native proficiency is an unrealistic standard for non-native speakers. As Modiano (2001: 340) pointed out, "Pressure to attain near-native proficiency may result in establishing then [the students] as auxiliary members of the culture which is represented by the prescriptive educational standard. Something not in harmony with their own self-image." Li (2006) further commented that using a native English-based pedagogical model to measure non-native English speakers' competency is inappropriate. Matsuda (2003) also suggested that there should be an integration of World Englishes into ELT curriculum. He proposed an ELT curriculum model in which students are exposed to English speakers of World Englishes from various language and cultural backgrounds and believed that English should be perceived as a pluralistic language rather than a monolithic one. Matsuda suggested that this ELT curriculum model should aim to increase students' awareness of World Englishes.

Using English as a lingua franca is a legitimate call if one looks at the present English worlds. $80 \%$ of verbal exchanges in which English is used as a foreign or second language are between non-native English users but not native speakers as estimated by Gnutzman (2000). The total of EFL/ESL learners was 1100 millions as at Year 2000 according to the statistics from the British Council. This figure had already outnumbered, by almost four times, the present total population of native English speakers (328 million) in the world (Levis, 2009). With the use of English as an international language for work, study or pleasure, the number of English learners can only be expected to grow continuously in such a globalised world. Li (2006) reckoned that English is meant for intranational communication in the outer circle in terms of functions, native speakers of the inner circle are often not present. As estimated by Gnutzmann (2000), 80\% of verbal exchanges in which English is used and involve no native speakers but non-native speakers. One may then ask whether native English should be set as the norm for the rest of the English worlds.

As discussed previously, scholars have been advocating the concept of world Englishes while research found learners to date still prefer native English as the standard for teaching and learning. It is the learners' past experiences, both from the classroom and the society, combine to affect their attitudes to native English. Looking at the EFL examinations around the globe (e.g. Cambridge ESOL exams, TOEFL, IELTS, etc.) and the local university entrance tests, almost all listening components were read aloud by native speakers of the inner circle which inevitably set native English as the norm and model of teaching and learning.

If we are to turn this situation around, the most fundamental group of people who might be able to facilitate this are the in-service teachers as well as the pre-service teachers. The reason is simple: learners as a matter of fact have no choice over what materials they would be exposed to in the classroom or how they are assessed, but the teachers. Teachers are the gatekeepers of what materials should be used in the classroom, what should not. Teachers should hence take the lead and revisit the definition of "standards and norms" in their own teaching and learning context and understand the social and pedagogical implications of multilingualism and its relations to the Englishes in the world. They should first consider whether to use localized English materials, non-native English models and materials in their classrooms and expose students to different varieties of English in order to broaden students' knowledge and enhance the awareness and recognition of World Englishes.

In response to the responsibility of EFL teachers mentioned above, this paper will focus on investigating a group of pre-service teachers because of the distinct dual identities they possess-learners today and teachers-to-be. It will be meaningful to see how this group of participants perceives native English and non-native English from a hybrid perspective. The focus of this paper is to see if pre-service teachers, at the time as EFL learners, have a preference to native English accent like what the precious studies had found; and whether they can distinguish their preferred accent from the many different others. If they cannot, what are the implications to EFL teaching and learning? What can teacher trainers do to rectify the situation?

\section{RESEARCH QUESTIONS}


The aim of this paper is to examine pre-service teachers' preference to different English accent in order to draw implications to EFL teaching and learning. This general objective can be broken into three constituents:

1. Do pre-service EFL teachers prefer native English to be the model of teaching and learning?

2. Which country/countries' English accent do the pre-service EFL teachers prefer?

3. Can the pre-service EFL teachers identify their preferred accent?

\section{METHOD}

\section{Design}

Three instruments were used to gauge participants' perception of accent in teaching and learning: a listening task, a survey questionnaire and focus group interview.

\section{Participants}

Twenty one third year students from a teacher training institute in Hong Kong took part in this project. They were all English education major students who had just finished 6 weeks of block teaching practice. Given that there were more female students studying language education than males, there were 15 female participants and 6 male participants. One participant was born in China and the rest were born in Hong Kong. 16 of them had been learning English for more than 15 years; 4 had been learning English for 11-14 years; one had been learning English for less than 10 years. Their age ranged between 21-23 years old.

\section{Questionnaire}

To investigate a larger group of participants' opinion towards different English accents used in different contexts, a questionnaire was administered. Before participants were invited to take part in the project, the project investigators gave a general briefing to the students, of which general objectives, the details of the focus group interviews were outlined. One week after the briefing, the two investigators invited those students who were voluntarily willing to take part in the project to fill in a questionnaire.

The questionnaire had been piloted and several wordings of the questionnaire items were amended based on the respondents of the pilot study. The face-to-face questionnaire survey was carried out on 29 October 2009. It was successfully administered to 21 students; 21 valid questionnaires were collected. There were 28 items in the questionnaire and 6-point Likert scale was employed (6: strongly agree, 1: strongly disagree). Participants were also given a choice of choosing "don't know" as their answer. The aim of the questionnaire was to investigate whether they preferred using local variety of English (i.e. Hong Kong or Mainland Chinese) as the teaching and learning model, and how they perceived the issue of intelligibility. The questionnaire was in English and respondents were not given a time limit but allowed to take their time to finish the questionnaire. A reliability test on the revised questionnaire items was run to determine their internal consistency. The reliability coefficient (Cronbach alphas) was high, with an alpha value of 0.852 , meaning the internal consistency of the questionnaire items was high.

\section{Listening task}

To elicit participants' most preferred English accent and whether students can identify different varieties of accent, video clips featuring some TV drama series from four major native English speaking countries were shown to facilitate their choices. 16 adjectives of traits were provided for the participants to rate whether the accents they listened from the clips corresponded to them. Examples of traits were: educated, arrogant, powerful, and friendly. The four English speaking countries were: Australia, Canada, New Zealand, and the UK. Each TV drama series clip lasted for approximately 2 minutes. Apart from rating how the adjectives of traits corresponded to the speakers they listened to in the clips, participants were also asked to identify the accent of the speakers. They would be asked five comprehension questions which were related to the content of the conversations in order to examine whether participants understood the dialogues.

\section{Focus group interview}

The aim of the focus group interview was to further allow participants to explain their preference on different accents. In order to achieve this, the focus group interview consisted two parts: 1) a simple questionnaire which interviewees were asked to fill in before the start of the interview and the questionnaire items would be used as prompts in the focus group interview; and 2) face-to-face in-depth focus group interviews.

Five participants volunteered to join the focus group and were interviewed in this study. The focus group interview took place on 14 November 2009 and was moderated by two moderators (two investigators, or one investigator plus the research assistant). At the beginning of the focus group interview, participants were given 6-8 minutes to complete the questionnaire specifically for the focus group interview. Respondents were reminded to provide a brief justification of their preferences. To further tap into the participants' choice of the most preferred accent(s), sound clips featuring two politicians of local English accents (local Hong Kong variety of English and local mainland Chinese variety of English) were used as prompts. Participants were encouraged to speak their mind using the language they felt the most comfortable with. After discussing their preferences of accent, the investigator then proceeded to discussion of each of questionnaire items. Participants took turns to respond and give reasons for their choices. The focus group interview took an open-ended format to allow participants to provide support or views on a topic whenever they wished to. The focus groups were both audio- and video-recorded with the participants' consent; the audio-visual data were transcribed and analyzed. 


\section{DATA ANALYSIS}

Data collected from the questionnaire were analysed using SPSS. Descriptive analyses (means and standard deviations) were mainly used to project a larger group of participants' general preference to different accents. The focus group interviews data were first transcribed by a research assistant, whereupon the researcher analyzed the data qualitatively and thematically. All analyses followed the thematic approach in order to discover overarching themes that might emerge from the data, both data from individual participant teachers and across all participant teachers (Daly, Kellehear, \& Gliksman, 1997). The process involved the identification of themes through "careful reading and re-reading of the data" as Rice \& Ezzy stated (1999: 258). It is a form of pattern recognition within the data, where emerging themes can be categorized for analysis.

\section{RESULTS}

\section{RQ1: Do the pre-service EFL teachers prefer native English to be the model of teaching and learning?}

Based on the results found from the questionnaire, pre-service EFL teachers tended to prefer using native English as the teaching and learning model in general (M: 4.09, S: 1.22). The results echoed the results of the previous studies (Bayard et al, 2002; Timmis, 2002). For learning, from an English learner's point of view, most of the participants ( $n=4)$ preferred speak English like a native speaker because speaking English like a native speaker may lead to "effective communication" or "career advancement" as described by two of the participants in this study. A respondent stated,

"I prefer sounding like a native speaker from BBC (British Broadcast Corporation) too, because I think it's the origin of English and others learned BBC before they developed their own accents. ..There is no point I would like to sound like a Chinese English speaker... I know I live in Hong Kong, but I would like to go for the best." (52-57)

Respondents also explained that textbooks and assessment also imposed an impact on her perception to accent.

When I was in school, the teachers told me that many examiners regarded British English as the standard accent. So I think if I do not correct, then it may be a disadvantage during examination. (340-342)

In terms of teaching, participants agreed in the focus-group interview that if features of the local/localized English accent occurred in the classroom, they would correct their students' pronunciation errors by giving out the correct ones because they believed teachers should teach "standard English and the right pronunciation" and native English was the "standard English". Also, they believed Hong Kong English "may confuse the foreigners". In other words, participants held negative opinions and attitude towards using local variety of English as the norm for teaching and learning.

As one of the respondents mentioned,

Yes. Of course, you're teaching the students the native English accent because when you are teaching the students, I think you should consider the intelligibility of the foreigners (native speakers)...I think the matter of choosing what accent is...you should give them the native speakers' way of...English speaking so that they know what is outside the world. $(364-378)$

In this study, only one respondent in the focus group interview expressed her preference over using Hong Kong English as the learning and teaching model because she believed Hong Kong English accent symbolised her cultural identity and intelligibility was the ultimate purpose of communication. A previous study by Li (2009) had similar result that only $20 \%$ of Chinese EFL users concerned the issue of intelligibility. This study reinforced what Levis (2005) commented on how the issue of intelligibility had been often overlooked.

\section{RQ2: Which country/countries' English accent do the pre-service EFL teachers prefer?}

According to the questionnaire, UK accent was found to be the most preferred accent among the participants and in the focus group interview, pre-service EFL teachers also preferred the UK accent as the teaching and learning model because Hong Kong was a British colony and they perceived British accent "high class, elegant, professional" and "the best standard" while American English was considered as "non-standard", "low class".

This result echoed what Dalton-Puffer et al. (1997) found in Austria. In their study, EFL students was asked to listen to unidentified speech samples of both native and nonnative speakers of RP and GA then rate the speakers on a series of positive descriptors. The RP accent was ranked the highest on most descriptors and Austrian-British was ranked the lowest - the one which was similar to the participants' own accent. This result has shown a tendency of accent stereotypes. In other studies like Dalton-Puffer et al's (1997:122), participants also rated the speaker with the RP accent as "being the most educated, organized, and courteous, among other positive descriptors" — similar to that of the present study found.

All respondent also indicated that they chose British English as their preferred accent because Hong Kong was once a British colony. Due to historical reason, choosing British accent seemed to be a natural choice as one of the respondents gave a representative view in the focus group interview,

"Hong Kong was a British colony...So we prefer British accent...Because in my childhood time, I often listened to the British English, and I think it's comfortable to get this accent ... I think they sound like more professional and more elegant than American English. I think American English is a bit rude. (388-423)

\section{RQ3: Can the pre-service EFL teachers identify the preferred accent?}

Even the UK accent was mostly preferred by the pre-service teachers according to the result of RQ2, results of RQ3 showed that they were not able to identify the UK accent in the listening tasks. There were only 3 students $(14 \%, N=21)$ 
who could identify the UK accents perfectly in the listening tasks even most students thought that they could easily identify the UK accent (M: 4.14, S: 1.12).

This study has revealed a mismatch between these learners' own accent goals and their ability to perceive accents. The result is also on par with what Chiba et al. (1995) found. They found that despite the high ratings given to American accents, less than one third of the participants were able to identify them.

In sum, the results of this present study presented a picture that EFL learners tended to set native English for teaching and learning model and preferred UK accent most, although not all could actually identify their preferred accent when listening to speech samples. Evidence also showed there is a tendency of accent stereotyping and idealization of native English speech.

\section{DisCUSSION \& IMPLICATIONS}

The present study proved that pre-service teachers, who are considered to be more receptive to new concepts, were also found to be in favour of native English accent for teaching and learning. Participants of this study preferring native English speaking norms to local varieties in English can be explained by several reasons:

1) Assessments and teaching materials used in EFL classrooms.

The teaching and learning materials used in EFL classrooms in the expanding and outer circles have been predominantly written by native English writers whom have defined what English is and what is not. As Jenkins (2005) commented the hegemony of native English EFL materials used in the outer and expanding circles of which standards and norms were an unattainable goal for non-native speakers, even EFL teachers. Kramch (1998: 28) also claimed, "Traditional methodologies based on the native speaker usually define language learners in terms of what they are not, or at least not yet." It is therefore inevitable for learners to view native English an ideal model for learning and teaching.

2) Status of native English teachers

The introduction of Native English Teachers (NET) Scheme also implied and reflected an unequal status between local English teachers and native teachers in Hong Kong while native English teachers were given higher salary, assigned with different job duties unlike that of the local English teachers. Most native teachers were assigned to teach classes with higher ability for different practical reasons which inevitably projected an adverse effect to EFL learners that native English teachers were for students with higher abilities and native English teachers were the ideal language learning models but not other varieties of English. Michael Tien, former chairman of Standing Committee on Language Education and Research (SCOLAR) in Hong Kong also reiterated in public media that native English teachers were of high standard of teaching effectiveness and served better language models for language learning (ATV, 2009). One may ask whether native speakers are necessarily good language models. Sociolinguists had the same answer (e.g. Kirkpatrick, 2007; Li, 2009) while Vivian Cook (1999:186) had the representative answer: "Native speakers are not necessarily aware of their knowledge in a formal sense, nor could they explain how they ride a bicycle" and she counter-argued what Stern (1983) put forward: native English teachers have (a) a subconscious knowledge of rules, (b) an intuitive grasp of meanings, (c) the ability to communicate within social settings, (d) a range of language skills, and (e) creativity of language use. Cook believed all the above were debatable.

3) Historical reason that Hong Kong was a British colony.

Participants mentioned that they preferred learning British English because they were brought up in a British colony. To them, learning British English seemed to be a natural model and norms for language learning and teaching. With the 100 years of colonial impact from the British government, education system, textbooks, teaching pedagogy, school setting and school administrative setting were all "borrowed" from the British model unfortunately without considering much of the local characteristics hence the British framework of teaching and learning had been deeply rooted in the minds of both teachers and students.

Considering this, pre-service teachers should be made to know that native English norms should not be imposed on EFL learners and the issue of intelligibility should also be emphasized and addressed. When assessing non-native English speaking students, they should be aware of the fact that no one should see L2 component of multicompetence to be identical to the monolingual's L1 because multicompetence is intrinsically more complex than monolingualism. Teacher educators should make pre-service English teachers understand the prominence of the native speaker in language teaching would create an unattainable goal for students. Teachers should therefore view students as multi-competent language users rather than deficient native speakers as coined by Cook (1991). As Stern (1992) explained L2 speakers developed L2 based on L1. Therefore, language teaching should concern with developing an L2 in a mind that already contains an L1. L2 difference from L1 should not be seen as language deficit from the native English standard. As Cook (1996:194-195) said, "People cannot be expected to conform to the norm of a group to which they do not belong...however, teachers... and people in general have often taken for granted that L2 learners represent a special case that can be properly judged by the standards of another group....L2 users have to be looked at in their own right as genuine L2 users, not as imitation native speakers."

Another important result found in this study was that this group of pre-service teachers unfortunately were not able to identify the UK accent from the rest of the native English accents - the accent they preferred most. In the study of Scales et al. (2006), English learners in America were not able to identify the accent of American speakers-the accent they listened to daily. When participants indicated that the UK accent was the most "educated" \& "elegant" and 
American accent was considered as "low class", obviously there was evidence that learners tended to make stereotyping and have idealization to certain native speakers. To avoid such stereotyping and idealization of accent which may adversely affect students' learning hence communication development, teacher educators should ensure pre-service English teachers understand non-native speakers as speakers in their own right, not as "approximations of native English speakers" as termed by Cook (1999) because the differences between monolingual speakers' language standard is of great difference from that of multilingual speakers of which is intrinsically more complicated.

\section{CONCLUSIONS}

Whether native English should be used as the norm in the context of EFL teaching and learning has been a debate for nearly two decades and there has not been any conclusion reached so far. However, it is not difficult to realize that the English Language has been changing and evolving for the past 1500 years and it will keep changing in the future, intelligibility will for sure serve as the very fundamental principle in the world of Englishes and native English standard will not stand as the "only" standard serving the globalised world, no matter we like it or not. Mutual intelligibility among different varieties of English will be inevitably required for intranational communication and interpersonal communication of different countries. Teacher trainers are therefore suggested to train EFL teachers in a way that matches the ongoing demands of the English worlds.

\section{REFERENCES}

[1] Bayard, D., Gallois, C., Ray, G. B., Weatherall, A., \& Sullivan, K. P. H. (2002). Evaluating English accents worldwide. Retrieved on 12 August 2016, from http://www.otago.ac.nz/anthropology/Linguistic/Accents.html.

[2] Chiba, R., Matsuura, H., \& Yamamoto, A. (1995). Japanese attitudes toward English accents. World Englishes, 14,77 - 86.

[3] Chugani, M. (2009). Newsline: Michael Tian views on the fine-tuning policy of English teaching in Hong Kong. Hong Kong: ATV.

[4] Cook, V. (1991). The poverty-of-the-stimulus argument and multi-competence. Second Language Research, 7, $103-117$.

[5] Cook, V. (1996). Competence and multi-competence. In G. Brown, K. Malmkjaer, \& J. Williams (Eds.), Performance and competence in second language acquisition (pp. 57-69). Cambridge: Cambridge University Press.

[6] Cook, V. (1999). Going beyond the native speaker in language teaching. TESOL Quarterly, 33, 185 - 209.

[7] Crystal, D. (1997). English as a global language. Cambridge: Cambridge University Press.

[8] Dailey-O'Cain, J. (1998, May). What does the second-language learner know about sociolinguistic stereotypes in the target language? Paper presented at the Canadian Association of Applied Linguistics conference, Ottawa, Canada.

[9] Dalton-Puffer, C., Kaltenboeck, G., \& Smit, U. (1997). Learner attitudes and L2 pronunciation in Austria. World Englishes, 16, $115-128$.

[10] Daly, J., Kellehear, A. \& Gliksman, M. (1997). The public health researcher: A methodological approach. Melbourne: Oxford University Press.

[11] Erling, E.J. (2005). The many names of English: A discussion of the variety of labels given to the language in its worldwide role. English Today, 81, 21(1), 40-44.

[12] Gnutzmann, C. (2000). Lingua franca. In Byram, M. (ed.) The Routledge Encyclopedia of Language Teaching and Learning. London: Routledge.

[13] $\mathrm{Hu}, \mathrm{X}$. H. (2004). Why China English should stand alongside British, American, and the other 'world Englishes'. English Today, 20 (2), 26-33.

[14] Hutchinson, T. \& Hutchinson, E. (1994). The textbook as agent of change. ELT Journal, 48, 315-328.

[15] Jenkins, J. (2006). Current perspectives on teaching World Englishes and English as a lingua franca. TESOL Quarterly, 40, $157-181$.

[16] Jenkins, J. (2007). English as a lingua franca: Attitude and identity. Oxford: Oxford University Press.

[17] Kachru, B.B. (1985). Standards, codification and sociolinguistic realism: The English language in the outer circle. In R. Quirk and H. Widdowson (Eds.), English in the world: Teaching and learning the language and literatures (11-30). Cambridge: Cambridge University Press.

[18] Kachru, B. B. (1997). World Englishes 2000: Resources for research and teaching. In L. E. Smith \& M. L. Forman (Eds.), World Englishes 2000 (pp. 209 - 251). Honolulu: University of Hawaii Press.

[19] Kirkpatrick, A. (2006). Which model of English: native speaker, nativised or lingua franca? In M. Saraceni \& R. Rudby (eds), English in the World. Global rules, global roles (pp.71-83). London \& New York: Continuum.

[20] Kirkpatrick, A. (2007). World Englishes. Implications for international communication and English language teaching. Cambridge: Cambridge University Press.

[21] Kramsch, C. (1993). Concept and culture in language teaching. Oxford: Oxford University Press.

[22] Kramsch, C. (1998). The privilege of the intercultural speaker. In M. Byram \& M.Ê Fleming (Eds.) Language learning in intercultural perspective: Approaches through drama and ethnography (pp. 16-31). Cambridge: Cambridge University Press.

[23] Ladegaard, H. J. (1998). National stereotypes and language attitudes: The perception of British, American and Australian language and culture in Denmark. Language \& Communication, 18, 251 - 274.

[24] Levis, J. (2005). Changing contexts and shifting paradigms in pronunciation teaching. TESOL Quarterly, 39, $369-377$.

[25] Levis, M. P. (2009). (ed.) Ethnologue: Languages of the World, $16^{\text {th }}$ edition. Dallas: SIL International.

[26] Li, D. C. S. (2006). Problemtizing empowerment on the merits and demerits or non-standard models of English in the EIL curriculum. Southeast Asia: A multidisciplinary Journal, 6 (1), 112-131.

[27] Li, D. C. S. (2009). Researching NNSs' views toward intelligibility and identity: Bridging the gap between moral high grounds and down-to-earth concerns. In Farzad Sharifian (ed), English as an International Language: Perspectives and Pedagogical 
issues (pp.81-118). Clevedon: Multilingual Matters.

[28] Matsuda, A. (2003). Incorporating world Englishes in teaching English as an international language. TESOL Quarterly, 37(4), 719-729.

[29] Mckay, S. L. (2002). Teaching English as an international language. Oxford: Oxford University Press.

[30] Modiano, M. (2001). Linguistic imperialism, cultural integrity, and EIL. ELT Journal, 55, 339 - 346.

[31] Rice, P., \& Ezzy, D. (1999). Qualitative research methods: A health focus. Melbourne: Oxford University Press.

[32] Scales, J., Wennerstorm, A., Richard, D., \& Wu, A. H. (2006). Language learners' perceptions of accent. TESOL Quarterly, 40 (4), 715-738.

[33] Seidlhofer, B. (2004). Research perspectives on teaching English as a lingua franca. Annual review of Applied Linguistics, 24, 209-239.

[34] Seidlhofer, B. (2006). English as a lingua franca in the expanding circle: What it isn't. In M. Saraceni \& R. Rudby (eds), English in the World. Global rules, global roles (pp.40-50). London \& New York: Continuum.

[35] Stern, H. H. (1983). Fundamental concepts of language teaching. Oxford: Oxford University Press.

[36] Stern, H. H. (1992). Issues and options in language teaching. Oxford: Oxford University Press.

[37] Timmis, I. (2002). Native-speaker norms and international English: A classroom view. ELT Journal, 56, 240 - 249.

[38] Widdowson, H. G. (1997). EIL, ESL, EFL: Global issues and local interests. World Englishes, 16, 135 - 146.

[39] Yano, Y. (2001). World Englishes in 2000 and beyond. World Englishes, 20, 119 - 131.

Ruth Wong is an assistant professor in the Department of English Language Education of The Education University of Hong Kong. Her research interests include second language teaching and learning, task-based teaching and learning, language arts and learning motivation. Her publications include research articles in international journals, chapters in books, articles in professional magazines, textbooks and teaching resources for Hong Kong secondary schools. 